\title{
Diameter of a draw zone — a case study from a block caving mine, Deep Ore Zone, PT Freeport Indonesia
}

\author{
H.A. Sahupala PT Freeport Indonesia, Indonesia \\ T. Szwedzicki AusWest Pty Ltd, Australia \\ R. Prasetyo PT Freeport Indonesia, Indonesia
}

\begin{abstract}
On the extraction level of the Deep Ore Zone (DOZ) Mine, PT Freeport, Indonesia, a tyre marker, and tramp material such as support elements, drilling accessories and a steel feeder reported to the drawpoints. The marker and the tramp material migrated from the Intermediate Ore Zone (IOZ) block caving mine, which was located $320 \mathrm{~m}$ above. The material started to report after a draw of 20,000-150,000 tonnes.

On assumptions of a cylindrical draw zone and on mass movement within the zone, the draw zone diameter was calculated. For 28 case studies of marker and tramp material movement the diameter of the draw zone was from 6.3-14.6 m, with an average diameter being about $12 \mathrm{~m}$. In one case, the calculated diameter of the zone was only $6.3 \mathrm{~m}$ indicating that void diffusion mechanism could take place. It was concluded that the diameter of draw zones increased with tonnage drawn but the diameter was not related to the rate of draw.
\end{abstract}

\section{Introduction}

In cave mining, width of the draw (extraction) zone is a fundamental mine design parameter and is used to determine the distance between drawpoints. For block caving, the optimal drawpoint spacing is where the draw zones of neighbouring drawpoints just overlap or touch each other. The size and shape of a draw zone is a function of design geometry (the drawpoint size) and the characteristics of broken rock (rock mechanical properties, fragmentation, material compaction and moisture).

With caving, a vertical cross-section of the draw zone is commonly assumed to be ellipsoidal. However, it has been noted that the draw zone can take the shape of a pipe or cylinder or can be irregular and may change in time with drawing. The development of the draw zone depends on the size distribution and packing of the material. High packing (compaction) results in the development of narrow extraction zones (Rustan, 2000).

Fragmentation and rock size distribution at the drawpoints determine migration and thus affect operational parameters including the mining layout (spacing between drawpoints), the selection of equipment (loadhaul-dump units (LHD) size and requirement for rock breakers), and the need for secondary blasting. Fragmentation in a cave zone is directly linked to rock mass conditions.

The finer the fragmentation of the rock, the closer the drawpoint spacing should be. Guidelines to determine drawpoint spacing and extraction zone geometry were published by Laubscher (1995) and by Hustrulid (1999).

A four year marker trial at a sublevel caving mine (Szwedzicki and Cooper, 2007) proved that the ore did not exhibit mass flow characteristics. The movement of over 700 markers was analysed and supplemented by a fragmentation study. From this analysis, it was concluded that for a rock mass with mining rock mass rating (MRMR) of 40-60 that produced a very well fragmented ore, the width of an extraction zone was 5-6 m wider than the width of the drawpoints. 


\section{$2 \quad$ Mining and geotechnical conditions}

Calculations of the diameter of a draw zone was carried out based on reports of a marker and tramp material at DOZ Mine, PT Freeport Indonesia. At the DOZ Mine 23 reports of a marker and tramp material from the IOZ Mine, located $320 \mathrm{~m}$ above, were documented.

\subsection{Mining conditions}

The Ertsberg East Skarn System (EESS) consists of a number of superimposed copper deposits and block caving mining took place starting from the highest deposit:

- The Gunung Biji Timur (GBT) block caving mine was in operation from 1980 through to 1993. Approximately 60 million tonnes of ore were recovered. The GBT cave reached the surface in 1986.

- The IOZ Mine block caving started production in 1994 at elevation 3,474 m, caving to the surface at 3,626 m (Sahupala and Szwedzicki, 2004). In 2003 the mine was closed with a total production of over 50 million tonnes of ore. The IOZ Mine connected vertically with the GBT mine. The footprint of the IOZ orebody was $330 \mathrm{~m}$ long by $220 \mathrm{~m}$ wide, with ore column heights of 150-220 m.

- The DOZ Mine started production in 2000, it is located about $320 \mathrm{~m}$ below the IOZ Mine and about $1,200 \mathrm{~m}$ below the surface. The DOZ block was at the elevation of 3,126 $\mathrm{m}$ to 3,474 $\mathrm{m}$ with the undercut level at 3,146 m, i.e. $20 \mathrm{~m}$ above the production level (Sahupala and Srikant, 2007). The DOZ block cave was designed to be more than $1,000 \mathrm{~m}$ long and more than $500 \mathrm{~m}$ wide. The mine had 857 drawpoints. Panel drifts were $4 \times 4.4 \mathrm{~m}$ with the width of the drawpoints being $3.6 \times 3 \mathrm{~m}$. The drawpoints were on $18 \mathrm{~m}$ centres along the panel drift, resulting in a column footprint of $15 \times 18 \mathrm{~m}$.

There was a vertical connection between the IOZ and GBT mine however, there was no data collected on migration of material from the upper mine to the lower mine.

\subsection{Geotechnical conditions}

A number of specific geological units were encountered in the DOZ Mine. However, a marker and tramp material were found in diorite and magnetite-fosterite, fosterite skarn, dolomite-marble and highly altered localised ore (HALO):

- diorite and forsterite rock mass form a hard, competent rock with very good ground conditions

- magnetite skarn is a massive unit of competent rock with fair ground conditions

- dolomite-marble and HALO rock have highly variable properties and local conditions ranging from poor to very poor.

Rock properties and rock mass classification are given in Table 1.

Table 1 Rock properties and rock mass classification

\begin{tabular}{llll}
\hline Rock Type & $\begin{array}{l}\text { Diorite, Magnetite } \\
\text { Skarn }\end{array}$ & $\begin{array}{l}\text { Forsterite } \\
\text { Skarn }\end{array}$ & $\begin{array}{l}\text { Dolomite-Marble } \\
\text { and HALO }\end{array}$ \\
\hline Specific gravity (SG) in situ & 2.88 & 2.9 & $2.66-2.77$ \\
SG in the cave & 2.4 & 2.41 & 2.22 \\
Rock quality designation (RQD) (\%) & $80-93$ & 56 & $22-51$ \\
Unconfined compressive strength (UCS) (MPa) & $110-130$ & 55 & $21-50$ \\
Rock mass rating (RMR) & $85-90$ & $50-55$ & $25-30$ \\
Classification of the rock mass (RMR) & Very good & Fair & Poor to fair \\
\hline
\end{tabular}




\section{$3 \quad$ Markers and tramp material}

When IOZ mine was closed, there were some steel items left on the extraction level (such as steel sets at drawpoints and panels, feeders to ore bins and some diamond drilling accessories). Those items were not salvageable or not salvaged because of deterioration that happened so quickly. These items were expected to be recovered at the DOZ drawpoints.

About 2.5 years after abandonment immediately below the IOZ Mine, where the DOZ Mine caving operations took place, the first tramp material from the IOZ Mine was noticed. Subsequently, in the following three years, in 28 drawpoints tramp material was reported 55 times. For further analysis, only reports of the first tramp material in each drawpoint were taken into consideration.

\subsection{Tyre marker}

During closure operations of the IOZ Mine, tyre markers were placed in selected locations on the extraction level. The tyres were from underground loaders and had a $1.6 \mathrm{~m}$ diameter. Each tyre had a unique number burnt into it and its exact location was recorded on mining plans.

For the first tyre marker recovered, Figure 1, the horizontal movement was calculated to be 2-3 m only. Over $320.5 \mathrm{~m}$ vertical distance, the horizontal movement could be considered negligible.

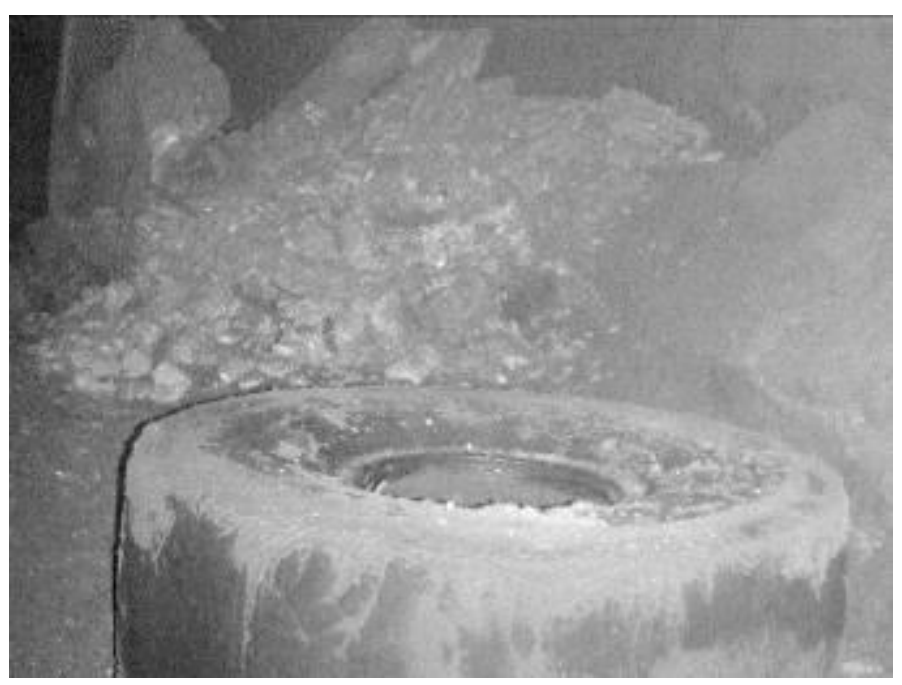

\section{Figure 1 A tyre marker in drawpoint P09-10W}

The tyre maker was recovered two years and three months after drawing operations started from a drawpoint below (Figure 5). That meant an average rate of tyre down movement of $0.37 \mathrm{~m}$ per day. 


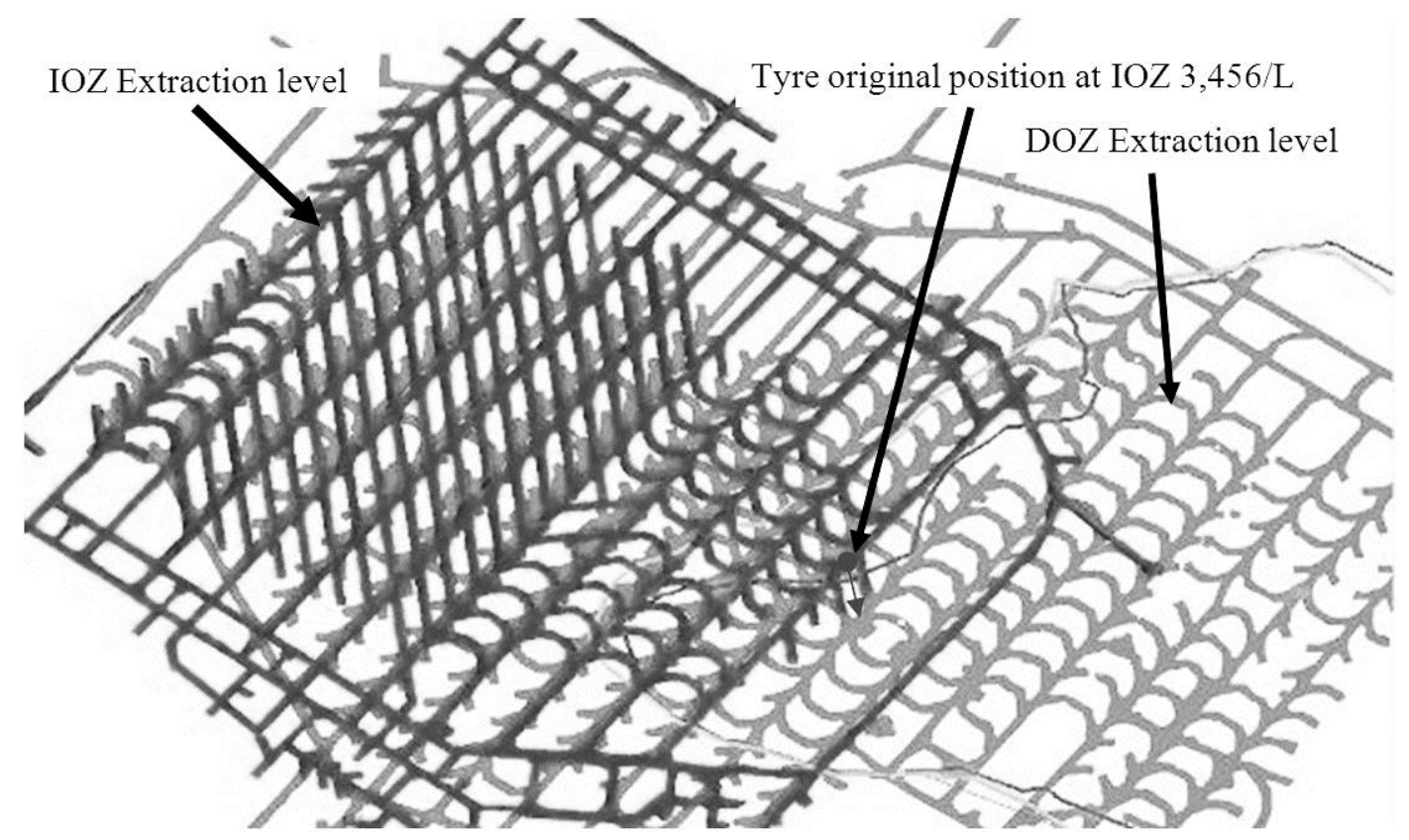

Figure 2 Position of the marker tyre on the IOZ and DOZ extraction levels

\subsection{Pipes, drill rods and steel ground support}

The following tramp material, mainly used as ground support elements at the IOZ Mine, was found: pipes, drilling rods, steel beams, wire mesh and bolts, and timber (Figures 3-6). In the majority of cases, they were steel beams, which were $3 \mathrm{~m}$ long with their $\mathrm{H}$-cross section being $0.2 \times 0.2 \mathrm{~m}$.

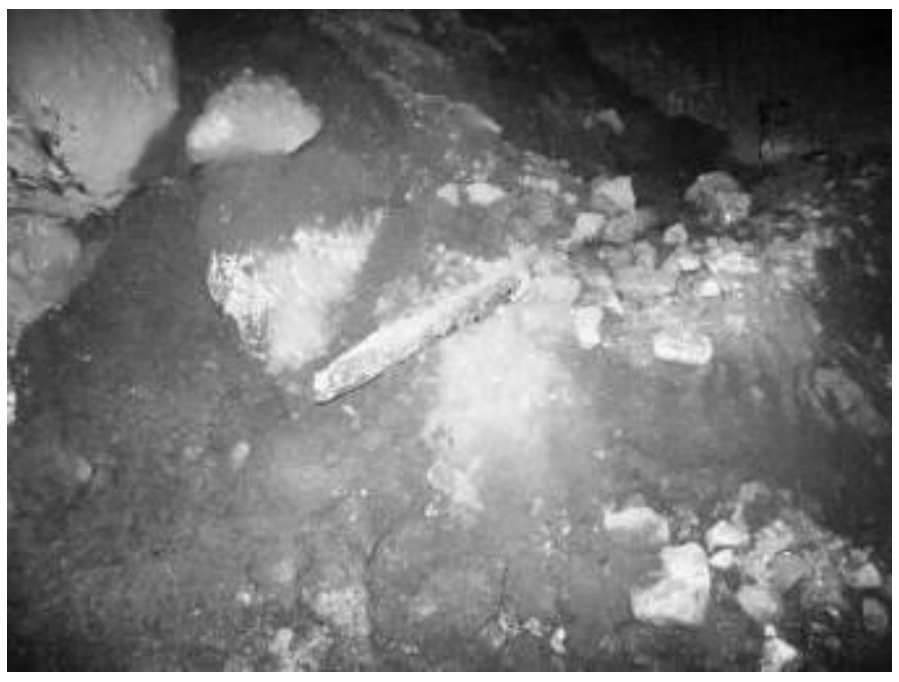

Figure 3 A service pipe at drawpoint P10-5E 


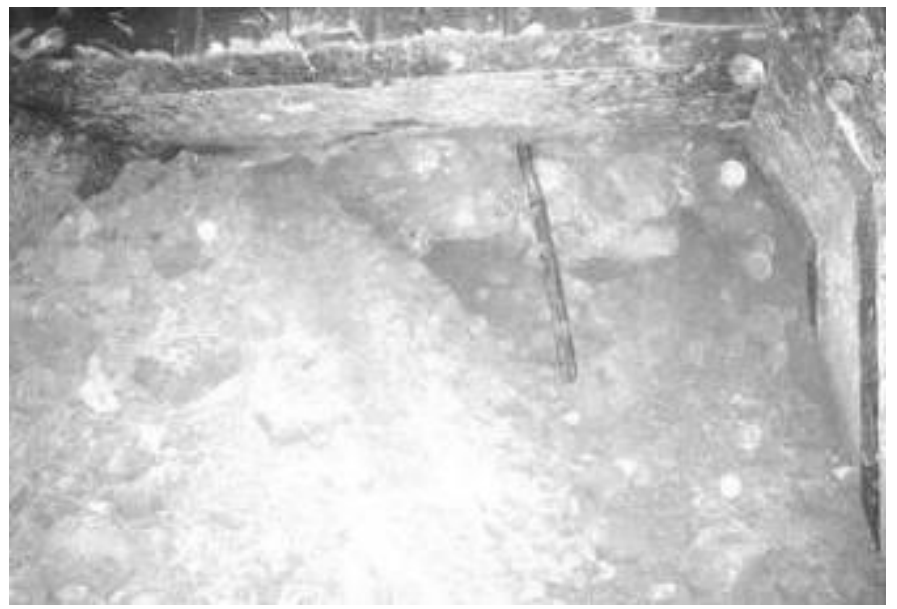

Figure 4 A drilling rod in a vertical position in P9-9E

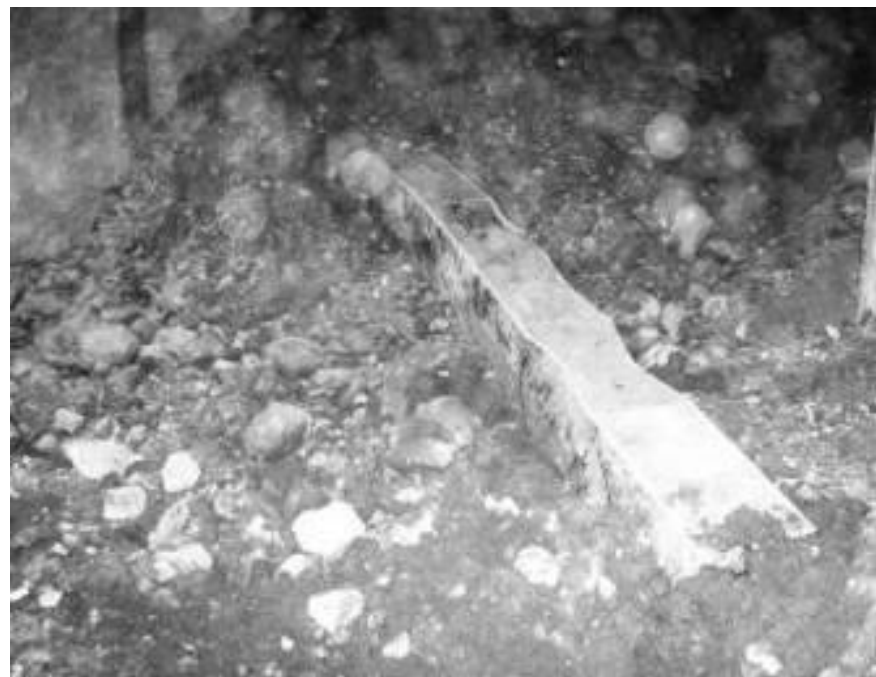

Figure 5 Steel beam in P9-11E

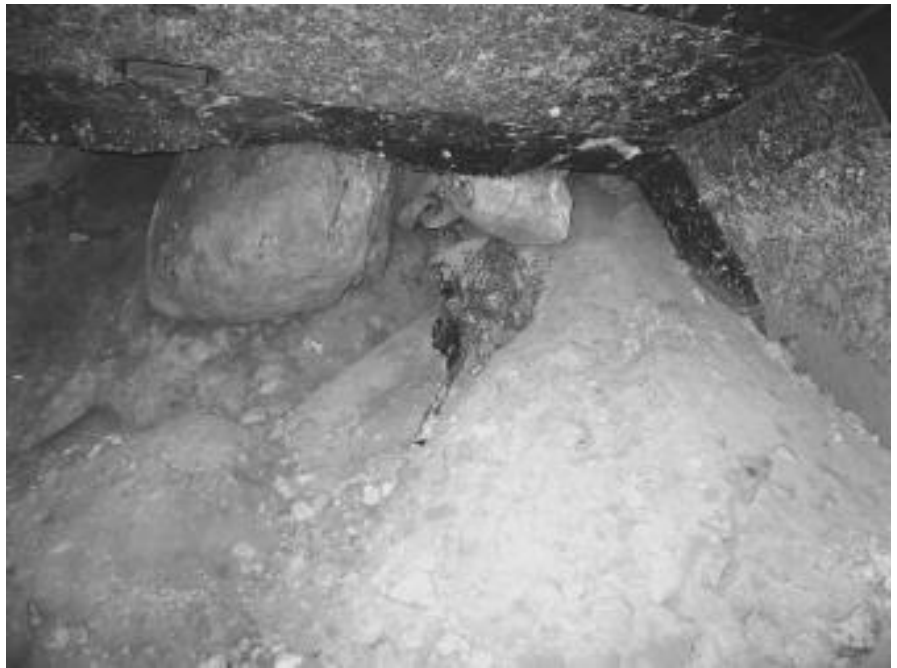

Figure 6 Mesh and bolt in P9-11W

The original location of service pipes, drilling rods, etc., on the IOZ extraction level was not known and so the horizontal movement could not be determined. 


\subsection{Feeder}

An interesting case study was that of a steel feeder left on the IOZ extraction level. The feeder, $3 \times 2 \times 1.5 \mathrm{~m}$, was found in a 'relatively good condition' in drawpoint on the DOZ extraction level (Figure 7). The feeder was recovered in the same drawpoint as the above mentioned tyre marker. As it was a consecutive report of the tramp material in the drawpoint, the appearance of the feeder was not used in calculations of the diameter of the draw zone.

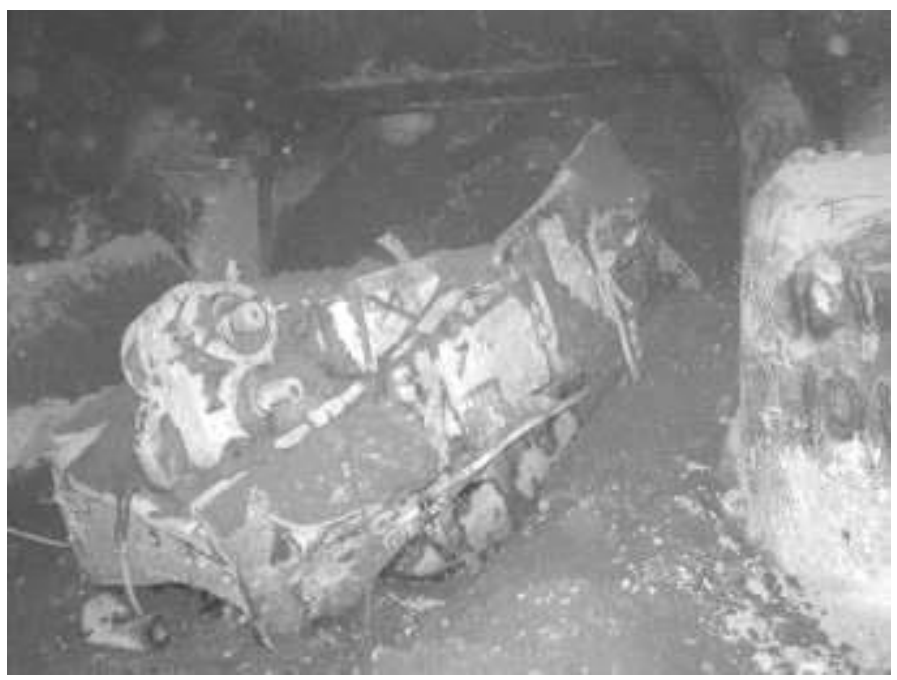

\section{Figure 7 Feeder on P09-10W}

Calculations proved that the feeder migrated horizontally for as much as $126 \mathrm{~m}$ to the south (over $324 \mathrm{~m}$ vertical movement). Possible explanations of such extreme horizontal movement could be attributed to rilling of the caved material (and the feeder) as the subsequent caving events took place in the direction of the progressive cave. Figure 8 shows the section and a plan of the feeder location and the feeder potential migration.

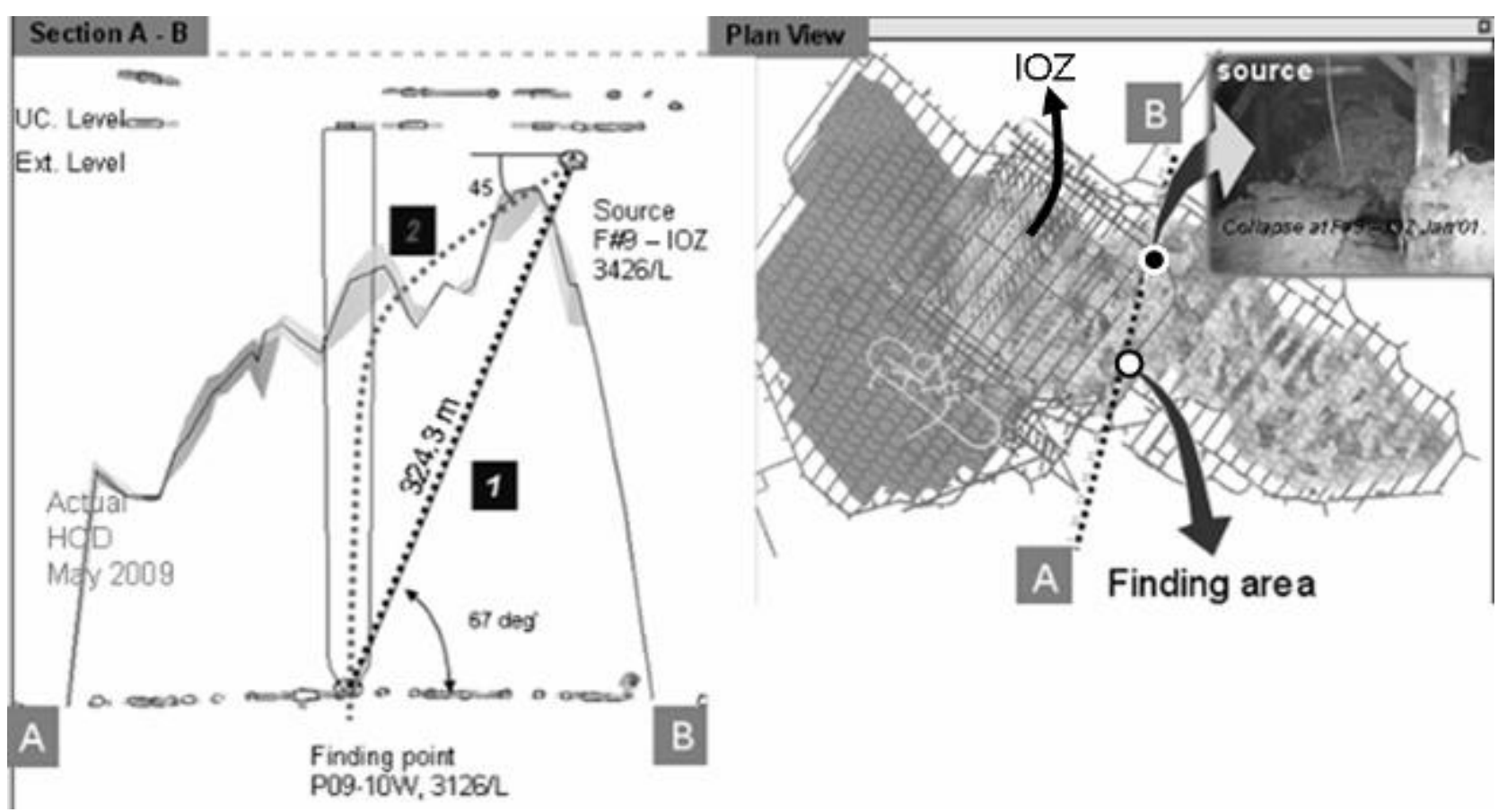

Figure 8 Schematic of feeder migration 
By estimating the time from the moment the DOZ cave intersected the location of a tyre marker and the feeder on the IOZ level and the distance between the IOZ and DOZ extraction levels, it was possible to calculate the average daily migration. The $1.6 \mathrm{~m}$ diameter tyre average migration was estimated to be about $0.37 \mathrm{~m}$. On assumption that the feeder rilled down (at an angle of $45^{\circ}$ ) from its original position to the same position as the tyre marker, it was estimated that the daily migration of the $3 \times 3 \times 5 \mathrm{~m}$ feeder was $0.15 \mathrm{~m}$, i.e. two and half times slower.

\section{$4 \quad$ Rock material in a draw zone}

Over $320 \mathrm{~m}$ between the DOZ and IOZ extraction levels, the ore drawn in each zone intersected various geological/geotechnical formations, namely: forsterite skarn, forsterite magnetite skarn, diorite, HALO and dolomite/marble. The mechanical properties of these rocks are given in Table 1. As shown in Figure 9, in each drawpoint, over the life of the mine, at least four different types of rock were drawn. However, for the purpose of classification, the material that was drawn together with the tramp material was assumed dominant.

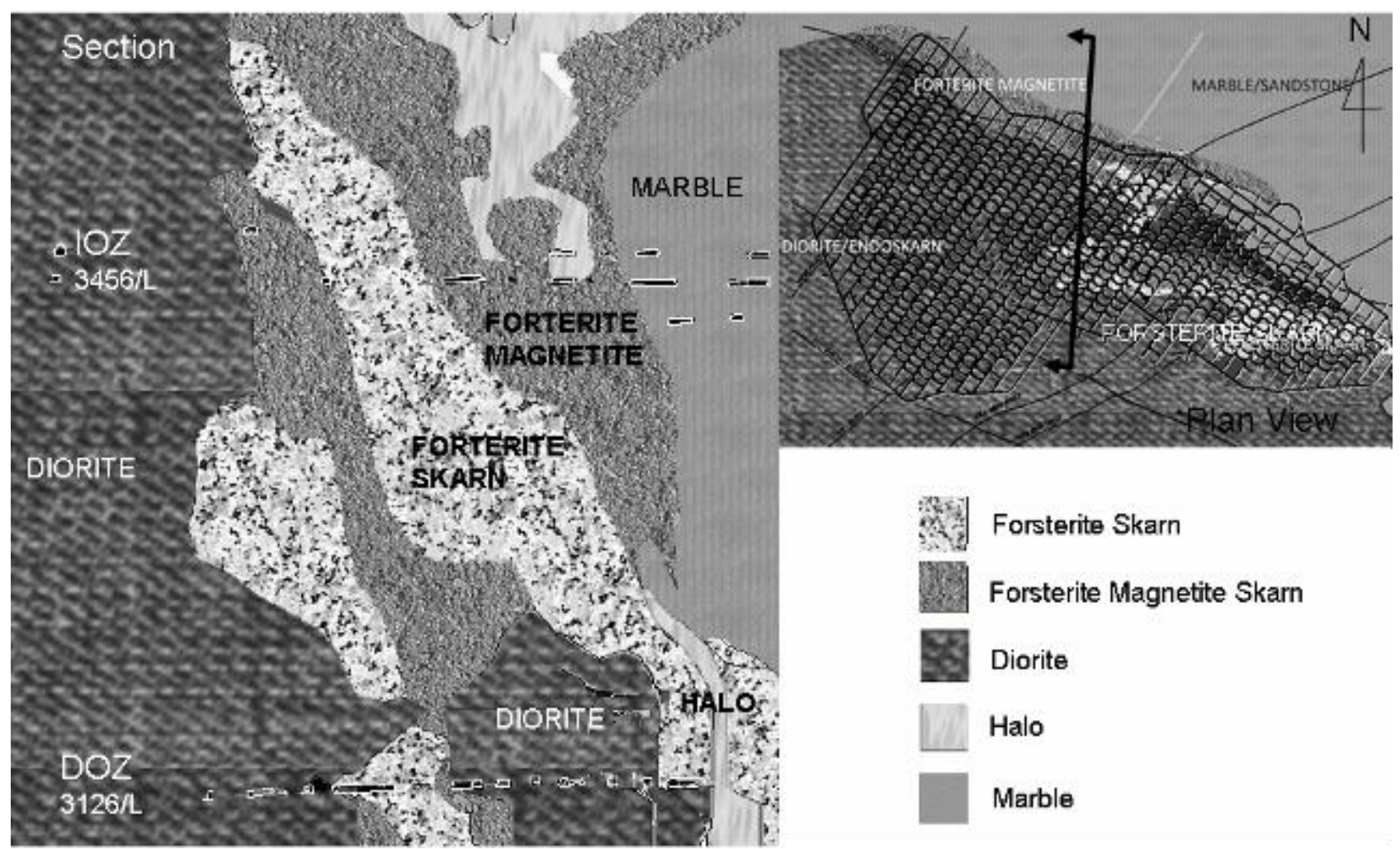

Figure 9 North-south geological cross-section showing various geotechnical formations that were intersected by the extraction zones

\section{Movement of rock fragments in the draw zone}

To calculate the diameter of the draw zone the following assumptions were made:

- the shape of the ore draw zone was cylindrical

- rock fragments movement/migration takes place as mass movement, i.e. all fragments within the draw zone move at the same rate

- tramp material flows at the same rate as rock fragments

- rock material in a draw zone was from various geological formations. 


\subsection{Shape of the draw zone}

Physical models indicated that the shape of the draw zone was elliptical. A number of field and laboratory studies shown that the ellipsoid is not always a true ellipsoid (Brown, 2007). Hustrulid (2000) assumed a cylindrical shape. According to diffusion void mechanism of material movement (Brown, 2007) the shape of the zone is highly irregular and changing as material progresses down. For calculation of the diameter of the draw zone with the tramp material progressing down, it was assumed that the flow takes place in a cylindrical shape.

\subsection{Movement of rock fragments}

Sand model studies, show that material in the centre, i.e. immediately above the draw area, moves at a faster rate than fragmented material at the periphery of a draw zone (extending towards the neighbouring draw zones), (Hustrulid and Kvapil, 2008). Should the material move slower at the periphery of the draw zone, the calculated diameter of the draw zone could be smaller than a factual diameter.

In a number of cases, several items of tramp material were reported in the same drawpoints. It was noted that a number of long and narrow elements like steel beams or timber were found at the drawpoints in a vertical position suggesting that the material moved in the centre of the draw zone.

\subsection{Movement rate}

In the draw zone, the rate of movement of fragments depends, among other things, on the size distribution and the shape of fragments. When fragments are of various sizes, the smaller fragments move in between the larger ones and flow faster. Fragments that are cubical or circular move faster than angular fragments or fragments of a different aspect ratio. Tramp material from the IOZ Mine found at the DOZ extraction level varied in shape and size. The smallest and probably cubical shape was that of a reamer, with the most elongated being steel beams with most of them up to $4 \mathrm{~m}$ long and $0.2 \times 0.2 \mathrm{~m}$ in width. While it can be assumed that the reamer was moving at the same rate as fragmented material, it is reasonable to assume that the remaining tramp material moved slower than the rock fragments. Should the material move slower, a larger volume of rock would be drawn before the tramp material reports at the extraction level. That is why the calculated diameter of the draw zone could be smaller than the actual diameter. However, for calculation of the draw zone diameter, it was assumed that fragmented rocks and tramp material moved at the same flow rate.

\section{Diameter of a draw zone}

To calculate a diameter of the draw zone, it was assumed that the draw zone was cylindrical with the height being $320 \mathrm{~m}$, which is the distance between the IOZ and the DOZ extraction level. The diameter was calculated by dividing the volume of the material drawn before the tramp material reported to the drawpoint below. The relation between the tonnage drawn and volume was determined using the in situ density of the various rocks and the swell factor of the caved rock.

The swell factor is a characteristic parameter of a rock mass and describes the volume change that occurs when the in situ rock mass is fragmented. The swell factor determines the in situ density of the caved rock and depends on fragmentation (uniformity and size), hardness of the rock, moisture content and on compaction due to the height of the cave column. The swell factor is a parameter difficult to determine and it may vary due to compaction and may change in time as the cave matures. Based on the observations, a swell factor of $120 \%$ was used for calculation of the draw zone diameter.

In a number of drawpoints, the tramp material was reported a number of times. Although it was possible that the subsequent reports of the tramp material were due to different shape and orientation of the material during the flow, it also could be inferred that the subsequent tramp material was not immediately over or in the centre of the considered draw zone. For the purpose of this analysis, only the first reports of the tramp material were taken into calculations.

The location of each drawpoint, type of marker/tramp material, type of rocks in which the marker/tramp material was found, tonnage drawn, draw rate and the calculated diameter for all 28 case studies are given in Table 2. 
Table 2 Draw control parameters and reported tramp material in very good ground conditions

\begin{tabular}{|c|c|c|c|c|c|}
\hline Panel & Tramp Material & Geology & $\begin{array}{l}\text { Tonnage } \\
(000 \text { 's })\end{array}$ & $\begin{array}{l}\text { Draw Rate } \\
\text { t/day }\end{array}$ & $\begin{array}{l}\text { Calculated } \\
\text { Draw Zone } \\
\text { Diameter }(\mathbf{m})\end{array}$ \\
\hline P05-05E & Reamer bit & Diorite & 23.56 & 133.13 & 6.28 \\
\hline P07-08E & Steel beam & Diorite & 72.74 & 98.16 & 11.01 \\
\hline P08-09E & Steel beam & Diorite & 77.68 & 114.58 & 11.06 \\
\hline P08-08W & Steel beam & Diorite & 87.60 & 115.42 & 11.74 \\
\hline P07-07E & Steel beam & Diorite & 111.15 & 134.23 & 13.23 \\
\hline P07-09E & Steel beam & Diorite & 119.83 & 131.68 & 14.13 \\
\hline P08-08E & Steel beam & Diorite & 83.80 & 113.09 & 11.47 \\
\hline P08-09W & Steel beam & Diorite & 88.84 & 124.78 & 11.81 \\
\hline P09-11E & Steel beam & Diorite & 118.73 & 142.48 & 14.16 \\
\hline P09-10W & Tyre & Diorite & 119.93 & 141.93 & 14.26 \\
\hline P07-09E & Steel beam & Diorite & 119.83 & 131.68 & 14.13 \\
\hline P10-09E & Steel beam & Fosterite skarn & 55.56 & 118.21 & 9.66 \\
\hline P09-09E & Steel beam & Fosterite skarn & 46.69 & 121.90 & 8.86 \\
\hline P10-10E & Steel beam & Fosterite skarn & 46.13 & 125.36 & 8.79 \\
\hline P10-11W & Steel beam & Fosterite skarn & 61.10 & 133.41 & 10.16 \\
\hline $\mathrm{P} 11-11 \mathrm{E}$ & Steel arches & Fosterite skarn & 92.17 & 139.02 & 12.15 \\
\hline P11-09E & Steel beam & Fosterite skarn & 114.97 & 139.19 & 13.51 \\
\hline P10-10W & Diamond drill pipe & Fosterite skarn & 78.48 & 124.77 & 11.21 \\
\hline P09-03W & Steel beam & Fos-mag skarn & 52.42 & 107.42 & 9.20 \\
\hline P10-05E & Steel beam & Fos-mag skarn & 136.49 & 192.78 & 15.14 \\
\hline P10-05W & Steel beam & Fos-mag skarn & 147.11 & 202.63 & 14.59 \\
\hline P10-06W & Steel beam & Fos-mag skarn & 110.26 & 163.59 & 13.61 \\
\hline P10-07E & Steel beam & Fos-mag skarn & 122.03 & 167.40 & 14.04 \\
\hline P08-10E & Steel pipe & Fos-mag skarn & 120.97 & 113.48 & 13.77 \\
\hline P11-09W & Steel beam & Fos-mag skarn & 96.33 & 132.69 & 12.37 \\
\hline P10-09W & Steel beam & HALO 4 & 52.89 & 129.31 & 9.30 \\
\hline P11-01W & Steel beam & HALO 4 & 73.55 & 114.39 & 8.49 \\
\hline P11-01W & Steel beam & Marble & 74.29 & 124.02 & 8.69 \\
\hline
\end{tabular}

For all case studies, the diameter was in a range from 6.28-14.59 m with an average of about $12 \mathrm{~m}$. With a drawpoint width of $3.6 \mathrm{~m}$, this means that the diameter was about $8 \mathrm{~m}$ wider than drawpoints. It has to be noted that the smallest diameter of $6.28 \mathrm{~m}$ was calculated for a small size drill reamer.

It was noticed that irrespective of various geological origin of ore, i.e. various ground conditions, the diameter of the draw zones was found to be of similar range.

An interesting relationship was observed by plotting the relation between the diameter of the draw zone and the tonnage drawn (Figure 10). For a range of draw from 23,000-50,000 t there was a linear relationship with 
the diameter which ranged from 6-15 m. This indicates that the larger tonnage drawn, the larger the diameter. It can be concluded that the diameter of the draw zone, within the same draw height of $320 \mathrm{~m}$, was dynamic, i.e. increased with the tonnage drawn.

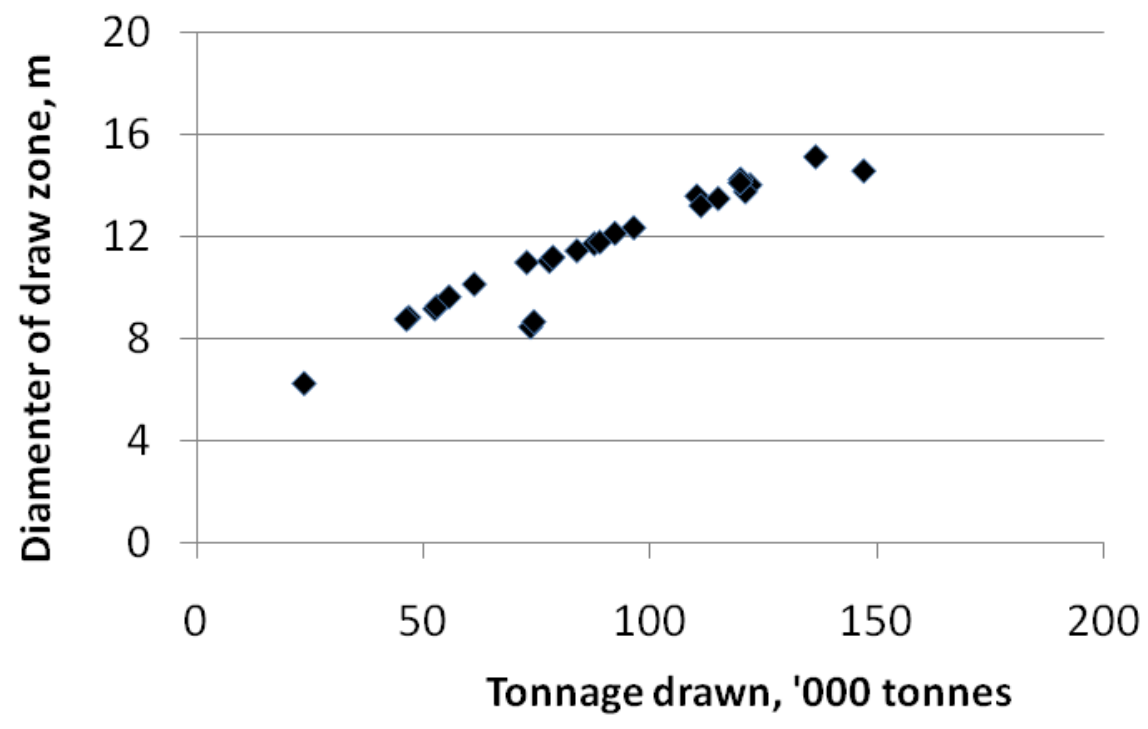

Figure 10 Increase in diameter of the draw zone with increased tonnage drawn from the drawpoints

An analysis of the draw rate for 28 drawpoints was carried out. The rate of draw from good to poor ground was in a range from 100-160 t/day. Analysis for draw between 100-160 t/day indicates that the rate of draw does not affect (or affects to a minimal extent) the diameter of the draw zone (Figure 11). In two case studies, for a draw rate of approximately $200 \mathrm{t} /$ day, the graph shows some increase in the diameter. However, this can be a statistical variation and more data is needed to confirm that observation.

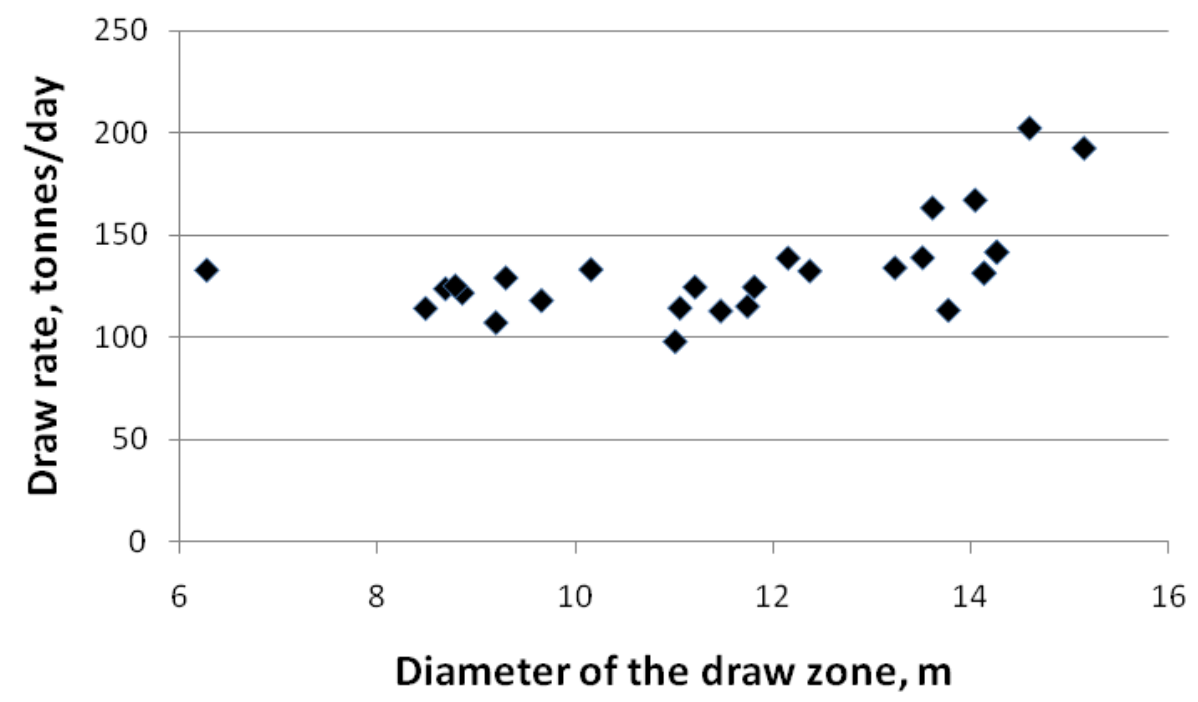

Figure 11 Diameter of the draw zone versus draw rate

\section{$7 \quad$ Fragmentation and draw}

An analysis was conducted to determine how fragmentation changes with the tonnage drawn, how the fragmentation affects the diameter of the draw zone and whether the fragmentation affects the rate of migration of fragments and the tramp material from the IOZ to DOZ Mine. Although it was evident that the fragmentation decreases overall as more tonnes are drawn, the variations in fragment size made statistical analysis unacceptable. The main reason was that large and oversize fragments continued to report occasionally to the drawpoints over their life. However, it was visually assessed that at the beginning of the 
caving in very good ground conditions, the median fragment size was $0.2-0.5 \mathrm{~m}$ (Figure 12). With material drawn to $100,000 \mathrm{t}$ the median fragment size was generally in the range of $0.02-0.07 \mathrm{~m}$ (Figure 13). In cases where tonnage exceeded $150,000 \mathrm{t}$ the median fragment size was less than $0.01 \mathrm{~m}$ with a relatively large portion of fragments less than $0.001 \mathrm{~m}$. From observations of the drawpoints, it was evident that very fine and fine material was flowing in between large and oversize blocks.

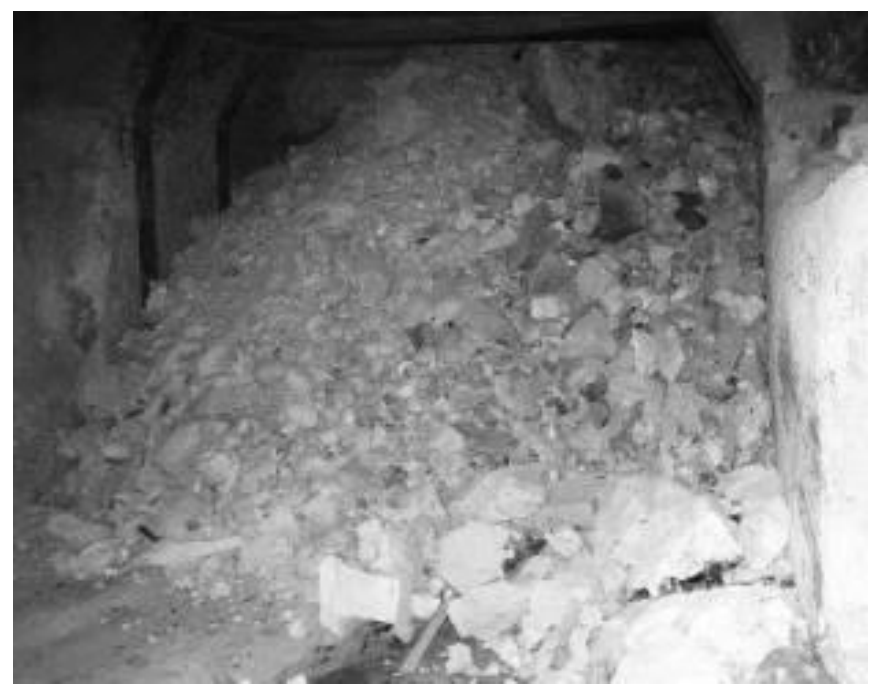

Figure 12 Fragmentation in early stage of draw

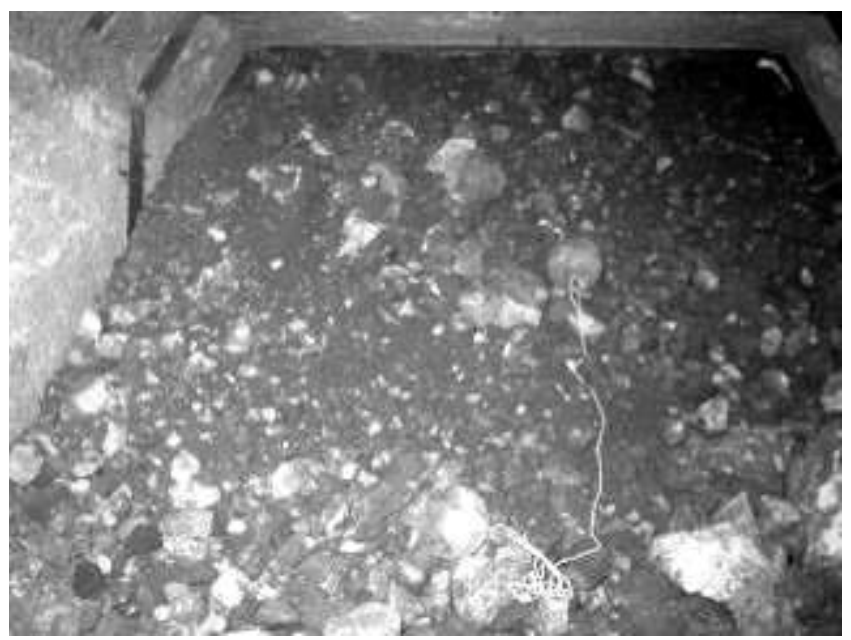

Figure 13 Fragmentation from a mature cave

\section{Conclusions}

PT Freeport Indonesia used block caving mining methods in three mines (GBT, IOZ, and DOZ) that were sited one over another. Twenty eight case studies on markers and tramp material reporting at the DOZ extraction level from the IOZ were documented (i.e. vertical distance of $320 \mathrm{~m}$ ).

- Markers and tramp material reporting from the IOZ Mine to the DOZ Mine allowed for back calculation of the diameter of the draw zones.

- For various ground conditions the diameter was in a range from 6.3-15 $\mathrm{m}$ with an average of about $12 \mathrm{~m}$. With a drawpoint width of $3.6 \mathrm{~m}$, this means that the diameter was about $8 \mathrm{~m}$ wider than drawpoints.

- Draw zone diameter appears to be related to the tonnage of drawn material. For 50,000 $t$ of drawn material the draw zone diameter was about $9 \mathrm{~m}$ and for 150,000 $\mathrm{t}$ it increased to about $15 \mathrm{~m}$. This 
indicates that the larger the tonnage drawn, the larger the diameter. It can be concluded that the diameter of the draw zone, within the same draw height of $320 \mathrm{~m}$, was dynamic, i.e. increased with the tonnage drawn.

- The rate of draw does not affect the diameter of the draw zone.

- A tyre marker and a feeder reported in the same drawpoint. The tyre marker showed almost no horizontal movement while the feeder was horizontally displaced for $126 \mathrm{~m}$ (over the draw height of $320 \mathrm{~m}$ ). This could be attributed to progressive caving resulting in the feeder rilling in the direction of the advancing cave.

- A drill bit was recovered unexpectedly fast, resulting in a calculated equivalent draw zone diameter of only $6.2 \mathrm{~m}$. This indicated that void diffusion mechanism was possible and that an assumption of mass movement might not be applicable in all cases.

\section{References}

Brown, T. (2007) Block Caving, Julius Kruttschnitt Mineral Research Centre (JKMRC), 2nd Edition, Brisbane, 2007.

Hustrulid, W. and Kvapil, R. (2008) Sublevel caving - past and future, in Proceedings 5th Conference on Mass Mining, Luleå, Sweden, 9-11 June, 2008.

Hustrulid, W. (2000) Method selection for large-scale underground mining, in Proceedings MassMin 2000, Brisbane, Australia.

Hustrulid, W. (1999) Mining Method, SME, 1999, Littleton, Colorado.

Laubscher, D. (1995) Cave Mining - State-of-the-Art, in Proceedings AusIMM Underground Operator's Conference, 13-14 November 1995, Kalgoorlie, Australia.

Rustan, A. (2000) Gravity Flow of Broken Rock - What is known and unknown, in Proceedings MassMin 2000, Brisbane, Australia.

Sahupala, H.A. and Srikant, A. (2007) Assessment of Pillar Damage at the Extraction Level in the Deep Ore Zone (DOZ) Mine, PT Freeport Indonesia, in Proceedings First International Symposium on Block and Sub-Level Caving, SAIMM, Cape Town, 2007.

Sahupala, H.A. and Szwedzicki, T. (2004) Geotechnical events leading to closure of an underground crusher, in Proceedings MassMin, Santiago, Chile, 2004.

Szwedzicki, T. and Cooper, R. (2007) Ore Flow and Fragmentation at Perseverance Mine, in Proceedings First International Symposium on Block and Sub-Level Caving, SAIMM, Cape Town, 2007. 